УДК 537.622.4

\title{
Precise Measurements of Magnetostriction of Ferromagnetic Plates
}

\author{
Dmitry V. Chashin \\ Dmitry A. Burdin \\ Leonid Yu. Fetisov \\ Nikolai A. Economov \\ Yuri K. Fetisov* \\ Moscow Technological University (MIREA) \\ Vernadskogo, 78, 119454, Russia
}

\begin{abstract}
Received 06.04.2017, received in revised form 06.07.2017, accepted 06.09.2017
The paper describes an automated setup for measurement of magnetostrictive strain in ferromagnetic plates and films. The setup uses standard foil strain-gauges and allows the strain measurement in the range 1-2000 ppm at magnetic field up to $2 \mathrm{kOe}$. Temperature of the sample under test is stabilized with $0.05^{\circ} \mathrm{C}$ accuracy and can be varied from $10^{\circ} \mathrm{C}$ to $80^{\circ} \mathrm{C}$. The sample can be rotated, settling the angle between its axis and magnetic field direction in the range $0^{\circ}-90^{\circ} \mathrm{C}$. The setup was used to measure magnetostriction vs. magnetic field dependences for metglas, nickel, and permendur plates. The magnetostriction over field derivatives were calculated, which are important for study of magnetoelectric effect in composite structures.
\end{abstract}

Keywords: magnetostriction, magnetoelectric effect, measurement setup, strain-gauge, ferromagnetic. DOI: 10.17516/1997-1397-2018-11-1-30-34.

\section{Introduction}

Magnetostriction is a property of ferromagnetic materials that results in changes in their shape or dimensions during the process of magnetization [1]. The magnetostriction arises due to anisotropic interaction between magnetic atoms and crystalline electric field. Investigation of magnetostriction plays important role in the research of new magnetic materials and mechanisms of their magnetization.

The magnetostriction is observed in a large number of magnetic materials and is characterized by a relative elongation of the sample $\lambda=\Delta l / l$, where $l$ is the length of the sample. The most common magnetostrictive materials are Ni, Fe, Co, NiFe, FePt, FeCo, and other alloys. The magnetostriction coefficient for these materials is in the range $\lambda \sim(10-100) \times 10^{-6}$. Extremely high magnetostriction up $\lambda \sim 10^{-3}$ was observed in rare-earth metals and their alloys, such as $\mathrm{Tb}, \mathrm{Dy}, \mathrm{TbFe}_{2}, \mathrm{DyFe}_{2}, \mathrm{~Tb}_{3} \mathrm{Fe}_{5} \mathrm{O}_{12}$, and the others [2]. At present the magnetostriction is used in various devices such as acoustic emitters and receivers, filters, frequency stabilizers, delay lines, microactuators etc. [3].

The magnetostriction gives rise to magnetoelectric (ME) effect in composite structures containing ferromagnetic and piezoelectric layers [4]. The ME effect in such structures is due to

*phantastic@mail.ru

(C) Siberian Federal University. All rights reserved 
combination of magnetostriction of the ferromagnetic layer and piezoelectric effect in the piezoelectric layer and results in generation of electrical voltage across the sample in external magnetic field. It was shown, both theoretically and experimentally, that efficiency of ME interaction is determined by the magnetostriction coefficient, saturation magnetic field of the ferromagnetic layer, and is proportional to the piezomagnetic coefficient $q^{(1)}=d \lambda / d H$. The ME effect is used to design ultrasensitive dc and ac magnetic field sensors, energy harvesting devices, new types of magnetic memory, tunable microwave devices, and other solid-state devices which have to operate in a wide range of magnetic fields and temperatures [5].

It follows, that study of magnetostriction vs. magnetic field dependences for ferromagnetic materials is of great scientific and practical interest. However, there were no commercially available installations allowing fast and accurate measurements of magnetostriction until now. This paper describes an automated setup which allows precise measurement of magnetostriction of ferromagnetic plates and ribbons for various direction of magnetic field at different temperatures. Capabilities of the installation were demonstrated by measuring the magnetic field, angular, and temperature dependences of magnetostriction of metglas, nickel, and permendur samples.

\section{Experimental set-up}

A block-diagram of the installation and its appearance are shown in Fig. 1. The installation consists of a magnetic system, control module, computer, and power supply. The strain gauge method was used to measure the magnetic field induced strain. A metal-film strain gauge was bonded on the sample with fast dry epoxy glue and connected into the bridge. The change of the sample size under magnetic field resulted in a change of the strain gauge resistance. The bridge misbalance voltage, which is proportional to the field induced deformation, was registered. A LabView based program was used to control the measurement and for data processing.
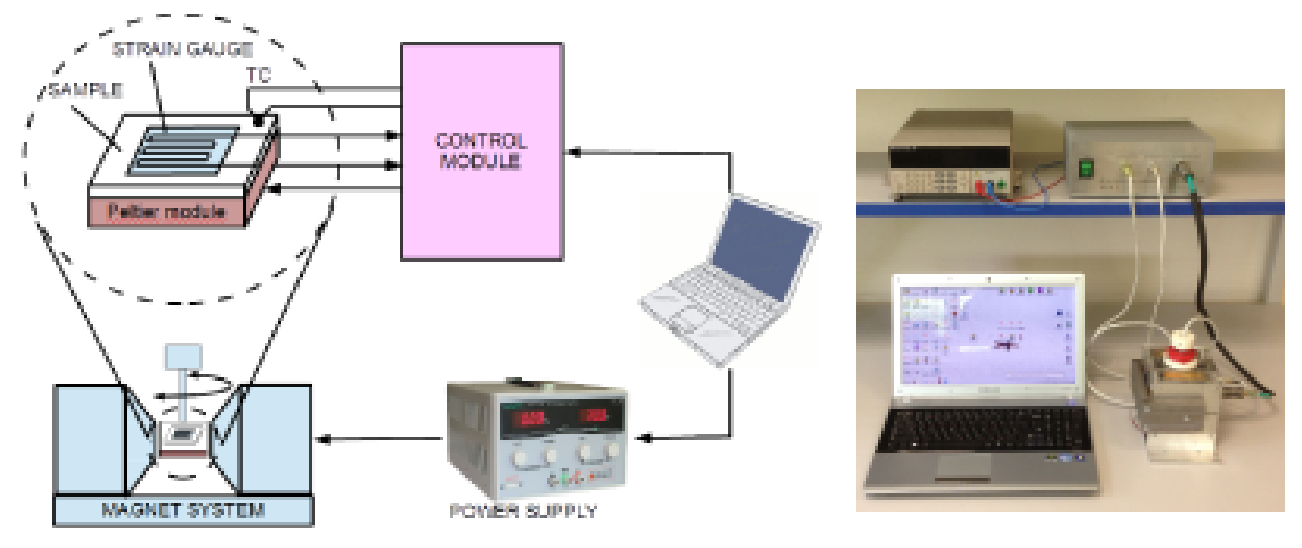

Fig. 1. Block-scheme and photo of the set up

The installation allowed measurements of magnetostriction of magnetic plates and ribbons with in-plane dimensions up to $\sim 2 \mathrm{~cm}$ and thickness from $\sim 20 \mu \mathrm{m}$ to $1 \mathrm{~mm}$. The dc field $H$ up to $2 \mathrm{kOe}$ could be directed in arbitrary direction with respect to the strain gauge axis by rotating the sample. A thermoelectric module was used to set and maintain the sample temperature with accuracy of $\sim 0.05^{\circ} \mathrm{C}$ in order to minimize temperature-induced voltage and to measure temperature dependences of magnetostriction in the range of $10^{\circ}-80^{\circ} \mathrm{C}$. The installation allowed 
measurements of magnetostriction in the range of $\lambda \approx(1-2000) \times 10^{-6}$ with accuracy better than $\delta \lambda \sim 1 \times 10^{-6}$. Power consumption of the installation was under $300 \mathrm{~W}$.

\section{Experimental results}

The measurements have been carried out for three samples: the metglas ribbon 2605S3A (FeBSiC), Ni plate, and permendur plate $\left(\mathrm{Fe}_{0.49} \mathrm{Co}_{0} .49 \mathrm{~V}_{0} .02\right)$ with dimensions of $20 \times 10 \times$ $0.02 \mathrm{~mm}^{3}, 20 \times 10 \times 0.2 \mathrm{~mm}^{3}$, and $20 \times 10 \times 0.4 \mathrm{~mm}^{3}$, respectively. The sample was placed between the poles of electromagnet so that the $H$ field was directed in the plane of the sample. The angle between the long side of the sample (strain gauge axis) and $H$ field direction was varied in the range of $\phi=0-90^{\circ}$ by rotating the sample.

Fig. 2 shows measured dependences $\lambda(H)$ for all three materials for the field $H$ applied parallel to the long side of the sample. It is seen that permendur demonstrates the highest saturation magnetostriction $\lambda_{s}=85 \times 10^{-6}$. Values for Ni $\lambda_{s}=-30 \times 10^{-6}$ metglas $\lambda_{s}=24 \times 10^{-6}$ are almost equal and differ only by the sign, which is in agreement with the literature data. The Fig. 2 also shows that metglas has the smallest saturation field $H_{S} \sim 40$ Oe, nickel has the intermediate field $H_{S} \sim 600 \mathrm{Oe}$, and permendur posses the highest field $H_{S} \sim 1.5 \mathrm{kOe}$.

Further, angular dependences of $\lambda(H)$ have been measured for all three samples. As an example, Fig. 3 shows dependences $\lambda(H)$ for metglas ribbon for different angles between the field $H$ and the long side of the sample. It is seen, that an increase in angle $\phi$ from $0^{\circ}$ to $90^{\circ}$ results in a decrease of the saturation magnetostriction from $\lambda_{S} \sim 24 \times 10^{-6}$ to $\lambda_{S} \sim-10 \times 10^{-6}$. Simultaneously, the saturation field $H_{S} \approx 40$ Oe practically does not change for different angles. The angular dependences of the magnetostriction for other samples had similar form and differ only in the value of saturation magnetostriction and saturation field.

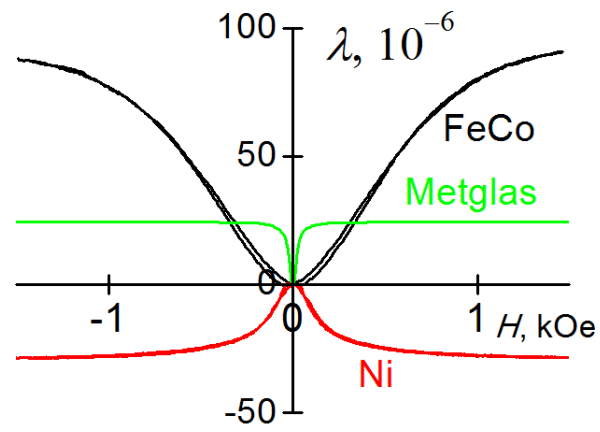

Fig. 2. The distribution of radial stress

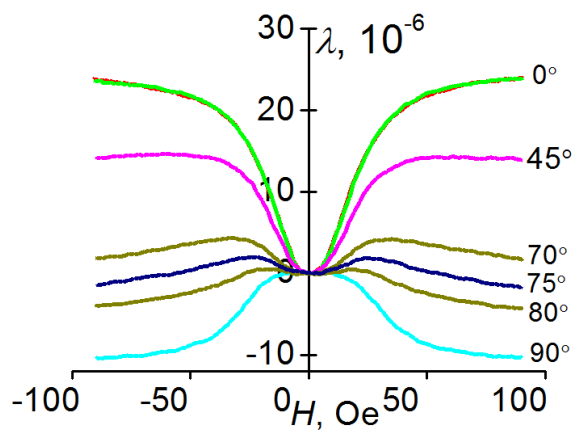

Fig. 3. The distribution of the angular stress

The precise measurements of the magnetostriction $\lambda(H)$ is required for calculation of nonlinear characteristics of ME effect in composite structures. It was shown [6], that nonlinearity of the $\lambda(H)$ dependence at high amplitude of ac magnetic field results in generation of the voltage harmonics. Amplitudes of the harmonics are proportional to the derivatives of the magnetostriction over the field: $\lambda^{(1)}=d \lambda / d H, \lambda^{(2)}=d^{2} \lambda / d H^{2}$, and $\lambda^{(3)}=d^{3} \lambda / d H^{3}$. The field dependences of the coefficients $\lambda^{(1)}(H), \lambda^{(2)}(H)$, and $\lambda^{(3)}(H)$ can be calculated by numerical differentiation of the curve $\lambda(H)$, which should be measured with high accuracy for this purpose. 
Fig. 4a shows, as an example, the $1^{s t}, 2^{d}$, and the $3^{d}$ derivatives of the $\lambda(H)$ for the metglas plate, obtained by the described method. The $2^{d}$ and the $3^{d}$ derivatives are multiplied by a factor of 5 and 20, respectively. The measured field dependences of the harmonics amplitudes $u_{1}, u_{2}$, and $u_{3}$ for the metglas - lead zirconate titanate (PZT) structure are shown in Fig. 4b [6]. It can be seen, that the curves in Fig. $4 \mathrm{a}$ and Fig. $4 \mathrm{~b}$ are coincide qualitatively. The maxima of the derivatives and maxima of the harmonics are placed at nearly same fields. The minima in the ME voltage corresponds to zero values of the derivatives.
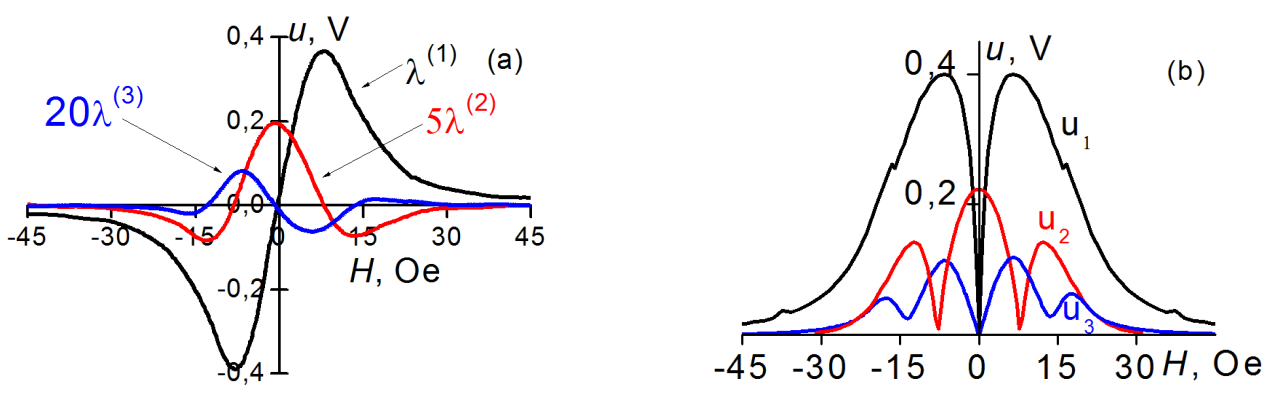

Fig. 4. Magnetic field dependences of: (a) coefficients $\lambda^{(1)}(H), \lambda^{(2)}(H)$, and $\lambda^{(3)}(H)$ for the metglas layer; (b) ME harmonics $u_{1} \sim \lambda^{(1)}, u_{2} \sim \lambda^{(2)}$, and $u_{3} \sim \lambda^{(3)}$ for the metglas-PZT structure

Fig. 5 demonstrates variation of the metglas ribbon magnetostriction with temperature in the temperature range of $10^{\circ}-80^{\circ} \mathrm{C}$. It is seen, that saturation magnetostriction decreases from $\lambda_{S} \sim 24 \times 10^{-6}$ to $\sim 18 \times 10^{-6}$ with increase in the temperature, while the saturation field does not change. Similar results have been obtained for two other samples. Temperature dependences of the magnetostriction can be used to explain temperature dependences of the amplitude of the ME voltage, generated by a composite structure, including those for nonlinear ME effect. Knowledge of the temperature dependences is important for design of thermally stable ME devices.

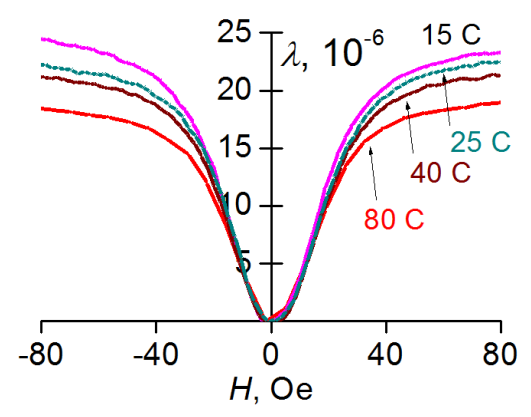

Fig. 5. Magnetostriction curves for metglas at different temperatures $T$

\section{Conclusion}

Thus, an automated installation for precise measurements of the magnetic field, angular, and temperature dependences of magnetostriction of ferromagnetic plates was designed and tested. The magnetostriction characteristics of the metglas, nickel, and permendur samples were investigated in magnetic fields up to $1.5 \mathrm{kOe}$ in the temperature range from $10^{\circ} \mathrm{C}$ to $80^{\circ} \mathrm{C}$. It was 
shown that high accuracy measurements of the magnetostriction provided by the installation may be used to find derivatives of the magnetostriction, which are important for investigation of nonlinear ME effects in composite structures and for development of various new ME devices.

The work was supported by the Ministry of Education and Science of Russia (project MK8.1183.2017) and the Russian Foundation for Basic Research (grant 16-32-14017).

\title{
References
}

[1] E. du Tremolet de Lacheisserie, Magnetostriction theory and applications of magnetoelasticity, CRC Press, Inc., Boca Raton, FL, 1993.

[2] L.Sandlund, M.Fahlander, T.Cedell, A.E.Clark, J.B.Restorff,M. Wun-Fogle, Magnetostriction, elastic moduli and coupling factors of composite Terfenol-D, J. of Appl. Phys., 75(1994), 5656-5658.

[3] A.G.Olabi, A.Grunwald, Design and Application of Magnetostrictive Materials, Materials and Design, 29(2008), 469-483.

[4] C.-W.Nan, M.I.Bichurin, S.Dong, D.Viehland, G.Srinivasan, Multiferroic magnetoelectric composites: Historical perspective, status, and future directions, J. of Appl. Phys., 103(2008), 031101.

[5] J.F.Scott, Aplications of magnetoelectrics, J. Mater. Chem., 22(2012), 4567-4573.

[6] D.A.Burdin, D.V.Chashin, N.A.Ekonomov, Y.K.Fetisov, L.Y.Fetisov, G.Sreenivasulu, G.Srinivasan, Nonlinear magneto-electric effects in ferromagnetic-piezoelectric composites, $J M M M$, 358-359(2014), 98-104.

\section{Точное измерение магнитострикции в ферромагнитных пластинах}

\author{
Дмитрий В. Чашин \\ Дмитрий А. Бурдин \\ Леонид Ю. Фетисов \\ Николай А. Экономов \\ Юрий К. Фетисов
}

Московский технологический университет

Вернадского, 78, Москва, 119454

Россия

$\overline{B \text { работе описана автоматизированная установка для измерения магнитострикиии пластин } и}$ пленок ферромагнитных материалов. В основе работы установки лежит тензометрический метод с исполъзованием стандартных пленочных тензодатчиков. Диапазон измеряемых деформаций составляет 1-2000 ррт в полях до $2 \kappa \vartheta$. Температура образца стабилизирована и может поддержсиваться с точностью $0.05^{\circ} \mathrm{C}$ в диапазоне $10-80^{\circ} \mathrm{C}$. Предусмотрен поворот образиа в пределах $0-90^{\circ}$ C. С помощью описанной установки были измерены полевые зависимости магнитострикции метгласа, никеля и пермендюра. Рассчитаны производные от магнитострикции по полю, необходимые для исследования магнитоэлектрического эффекта в композитных структуpax.

Ключевые слова: магнитострикиия, магнитоэлектрический эффект, измерительная установка, тензометрия, ферромагнетик. 